\title{
Effects of Exercise-Based Interventions on Fall Risk and Balance in Patients With Chronic Obstructive Pulmonary Disease A SYSTEMATIC REVIEW
}

Citation for published version (APA):

Delbressine, J. M., Vaes, A. W., Goertz, Y. M., Sillen, M. J., Kawagoshi, A., Meijer, K., Janssen, D. J. A., \& Spruit, M. A. (2020). Effects of Exercise-Based Interventions on Fall Risk and Balance in Patients With Chronic Obstructive Pulmonary Disease A SYSTEMATIC REVIEW. Journal of Cardiopulmonary Rehabilitation and Prevention, 40(3), 152-163. https://doi.org/10.1097/HCR.0000000000000513

Document status and date:

Published: 01/05/2020

DOI:

10.1097/HCR.0000000000000513

Document Version:

Publisher's PDF, also known as Version of record

Document license:

Taverne

Please check the document version of this publication:

- A submitted manuscript is the version of the article upon submission and before peer-review. There can be important differences between the submitted version and the official published version of record.

People interested in the research are advised to contact the author for the final version of the publication, or visit the DOI to the publisher's website.

- The final author version and the galley proof are versions of the publication after peer review.

- The final published version features the final layout of the paper including the volume, issue and page numbers.

Link to publication

\footnotetext{
General rights rights.

- You may freely distribute the URL identifying the publication in the public portal. please follow below link for the End User Agreement:

www.umlib.nl/taverne-license

Take down policy

If you believe that this document breaches copyright please contact us at:

repository@maastrichtuniversity.nl

providing details and we will investigate your claim.
}

Copyright and moral rights for the publications made accessible in the public portal are retained by the authors and/or other copyright owners and it is a condition of accessing publications that users recognise and abide by the legal requirements associated with these

- Users may download and print one copy of any publication from the public portal for the purpose of private study or research.

- You may not further distribute the material or use it for any profit-making activity or commercial gain

If the publication is distributed under the terms of Article $25 \mathrm{fa}$ of the Dutch Copyright Act, indicated by the "Taverne" license above, 


\title{
Effects of Exercise-Based Interventions on Fall Risk and Balance in Patients With Chronic Obstructive Pulmonary Disease
}

\author{
A SYSTEMATIC REVIEW
}

Jeannet M. Delbressine, BSc; Anouk W. Vaes, PhD; Yvonne M. Goërtz, MSc; Maurice J. Sillen, PhD;
Atsuyoshi Kawagoshi, PhD; Kenneth Meijer, PhD; Daisy J. A. Janssen, MD, PhD; Martijn A. Spruit, PhD

Purpose: Chronic obstructive pulmonary disease (COPD) is a highly prevalent disease characterized by airflow limitation and is associated with decreased balance and increased fall risk. Since falls are related to increased mortality, interventions targeting balance and fall risk could reduce morbidity and mortality. The objective of this review was to systematically assess the effects of exercise-based interventions on fall risk and balance in patients with COPD.

Methods: PubMed, Web of Science, EMBASE, and CINAHL were screened for randomized controlled trails and within-group studies evaluating effects of exercise-based interventions on fall risk or balance in patients with COPD. Data were presented in accordance with the Preferred Reporting Items for Systematic Reviews and Meta-Analyses statement.

Results: Fifteen studies were identified, 6 randomized controlled trails and 9 within-group studies. All interventions reported positive effects on balance outcomes. No studies reported fall risk. Taking current recommendations of balance outcome measures in patients with COPD into account, pulmonary rehabilitation combined with balance training had the highest effect size. Nine papers had concerns regarding bias, mostly due to the lack of blinding outcome assessors.

Conclusions: Exercise-based interventions have a positive effect on balance in patients with COPD. Pulmonary rehabilitation with balance training seems to have the most beneficial effect on balance. The effects on fall risk, as well as the longterm intervention effects remain unclear. A standardized balance assessment and research on long-term effects and fall risk are recommended.

Key Words: balance $\bullet$ COPD $\bullet$ exercise-based interventions • fall risk

Talls are an important cause of injury, injury-related disability, and death in older adults. Approximately $30 \%$ of adults aged $\geq 60 \mathrm{yr}$ fall each year and prevalence increases with age. ${ }^{1}$ There is strong evidence that patients with chronic obstructive pulmonary disease (COPD) are at an even higher risk of falling. ${ }^{2,3}$ Possible underlying mechanisms for impaired balance in COPD are lower limb muscle weakness, ${ }^{4}$ altered trunk mechanics, ${ }^{5}$ somatosensory deficits, ${ }^{4}$ altered postural control, ${ }^{6}$ comorbidities (eg, osteoporosis, osteoarthritis, cognitive impairment), and/or multiple medication use (eg, corticosteroids, psychotropics, cardiac medication). ${ }^{4}$ Furthermore, impaired balance has been shown to be associated with decreased physical activity in COPD and loss of independence in activities of daily living. ${ }^{7}$

Treatment and management of COPD are often focused on stabilizing the respiratory function and improving exercise capacity. ${ }^{8}$ Exercise training is even described as being the cornerstone of pulmonary rehabilitation (PR) in the 2013 American Thoracic Society/European Respiratory Society statement on PR. ${ }^{9}$ However, since falls are associated with an increased risk of all-cause mortality, improving balance and preventing falls are becoming a novel treatment target in patients with COPD, ${ }^{10}$ and measures of balance are now recommended to be included in the clinical assessment of patients with COPD. ${ }^{9}$

Although results of studies using exercise interventions to improve balance in patients with COPD are encouraging, to the best of our knowledge there is no systematic overview of the effects of the different interventions on balance and fall risk. ${ }^{11,12}$ Therefore, the purpose of this review was to systematically review the effect of exercise-based interventions on fall risk and balance in patients with COPD.

\section{METHODS}

This study was conducted and reported according to the Preferred Reporting Items for Systematic Reviews and MetaAnalyses guidelines. ${ }^{13}$

\section{INFORMATION SOURCES AND SEARCH STRATEGY}

A computerized literature search was performed on August 1, 2019, using PubMed, Web of Science, EMBASE, and CINAHL. The following key words and $\mathrm{MeSH}$ terms were

\footnotetext{
Author Affiliations: Department of Research and Development, CIRO, Horn the Netherlands (Mss Delbressine and Goërtz, and Drs Vaes, Sillen, Janssen, and Spruit); Department of Rehabilitation, Akita City Hospital, Kawamoto Matsuoka-cho, Akita, Japan (Dr Kawagoshi); NUTRIM School of Nutrition and Translational Research in Metabolism, Maastricht, the Netherlands (Drs Meijer and Spruit); Department of Health Services Research, CAPHRI School for Public Health and Primary Care, Faculty of Health Medicine and Life Sciences, Maastricht University, Maastricht, the Netherlands (Dr Janssen); Department of Respiratory Medicine, Maastricht University Medical Centre (MUMC+), Maastricht, the Netherlands (Dr Spruit); and REVAL_Rehabilitation Research Center, BIOMED—Biomedical Research Institute, Faculty of Rehabilitation Sciences, Hasselt University, Diepenbeek, Belgium (Dr Spruit).
}

The clinical fellowship of Dr Atsuyoshi Kawagoshi was funded by the European Respiratory Society (fellowship ID number: ERS CTF201810-
00456). The research work of Yvonne Goërtz is financially supported by the Lung Foundation Netherlands, Leusden, the Netherlands (grant 4.1.16.085).

The authors declare no conflicts of interest.

Supplemental digital content is available for this article. Direct URL citations appear in the printed text and are provided in the HTML and PDF versions of this article on the journal's Web site (www.jcrpjournal. com)

Correspondence: Jeannet M. Delbressine, BSc, Department of Research and Development, CIRO, Hornerheide 16085 NM, Horn, the Netherlands (jeannetdelbressine@ciro-horn.nl).

Copyright @ 2020 Wolters Kluwer Health, Inc. All rights reserved.

DOI: 10.1097/HCR.0000000000000513 
used combined with "AND" and/or "OR": COPD, chronic obstructive pulmonary disease, emphysema, chronic bronchitis, chronic airflow obstruction, exercise, training, strength training, resistance training, aerobic training, rehabilitation, postural balance, gait stability, gait instability, fall-risk, and risk of falls. All search terms, including the full search string and inclusion and exclusion criteria, are presented in Supplemental Digital Content 1, available at: http://links.lww.com/JCRP/A173. References from relevant articles were also screened for additional relevant papers.

\section{ELIGIBILTY CRITERIA}

Original studies that met the following criteria were included: (1) participants: patients with COPD; (2) study design: randomized controlled trials (RCTs) or within-group studies; and (3) outcomes: effect of an exercise-based intervention on balance and fall risk. Articles were excluded when (1) data were not described specified for COPD; (2) the duration of the intervention was $<14 \mathrm{~d}$; and (3) balance or fall risk was not reported as an outcome measure. In addition, non-English language articles, review articles, editorials, qualitative studies, methodology studies, and congress abstracts were excluded.

\section{DATA EXTRACTION AND METHODOLOGICAL QUALITY ASSESSMENT}

Two independent reviewers (J.M.L.D. and A.W.V.) independently screened titles and abstracts for eligibility and reviewed the full text of articles that met the inclusion criteria. Disagreements could be resolved by consulting a third reviewer (M.A.S.).

Study details and relevant results were obtained in a predesigned data abstraction form. For each study, first authors, participant characteristics (sex, age, and disease severity), exercise intervention, outcome parameters, and main outcomes were recorded. If necessary, authors of included studies were contacted directly to request additional data.

The risk of bias was independently assessed by 2 reviewers (J.M.L.D. and A.W.V.), using the risk of bias tool RoB2 ${ }^{14}$ for RCTs and ROBINS-I ${ }^{15}$ for non-RCTs. Both tools assess the risk of bias in several domains as well as the overall risk of bias. The risk of bias was assessed as low, some concerns, or high for RCTs; and low, moderate, serious, or critical in within-group studies.

\section{STATISTICAL ANALYSIS}

All between-group results and within-group results are presented as mean change $\pm \mathrm{SD}$. When the mean change $\pm \mathrm{SD}$ were not reported, data were requested from the corresponding authors. When no response was received or data were unavailable, results were calculated using methods described in the Cochrane Handbook. ${ }^{16}$ To be able to compare results from studies that did not use the same outcome measure, effect sizes were calculated using Cohen $d$. Results of the studies were compared with the minimal clinical important differences (MCID), recently reported by Beauchamp. ${ }^{17}$

\section{RESULTS}

\section{STUDY SELECTION}

Our search identified 76 unique studies, of which 15 fulfilled eligibility criteria. ${ }^{11,12,18-30}$ Reasons for exclusion were no balance or fall risk outcome reported $(n=3)$, not describing original data $(\mathrm{n}=1)$, results from patients with COPD were not specified $(\mathrm{n}=2)$, not meeting the mini- mum intervention duration of $14 \mathrm{~d}(\mathrm{n}=1)$, and no RCT or a within-group study design $(\mathrm{n}=1)$ (see Supplemental Digital Content 2, available at: http://links.lww.com/JCRP/ A174).

\section{RISK OF BIAS}

In 4 of the 15 studies included in this review, the overall risk of bias was low. ${ }^{12,18-20}$ One RCT $^{11}$ was considered at high risk of bias due to the concealment of the allocation sequence being unclear, as well as the blinding of outcome assessors. Two RCTs ${ }^{21,27}$ raised some concerns due to the lack of blinding of outcome assessors.

Three within-group studies ${ }^{22,24,31}$ were at serious risk of bias because of high rates and/or unblinded outcome assessors. Two within-group studies ${ }^{28,29}$ had a moderate risk of bias, while 3 within-group studies were rated as "no information," because of a lack of information in key domains of the bias assessment.

A summary of the results of the qualitative assessment is presented in Supplemental Digital Content 3, available at: http://links.lww.com/JCRP/A175. The complete results of the qualitative assessment can be found in Supplemental Digital Content 4 (RCTs; available at: http://links.lww.com/ JCRP/A176) and Supplemental Digital Content 5 (withingroup studies; available at: http://links.lww.com/JCRP/ A177).

\section{GENERAL STUDY CHARACTERISTICS AND POPULATIONS}

Study characteristics are described in Table 1. Six RCTs ${ }^{11,12,18,20,21,27}$ and 9 within-group studies were included in this review. ${ }^{19,22-24,26,28-31}$ Four RCTs ${ }^{11,20,21,27}$ also reported the within-group results. The corresponding authors were contacted if additional data were required, but unfortunately not all authors responded. When no response was received, the data were presented as not reported or means $\pm \mathrm{SD}$ were calculated according to the methods described in the Cochrane Handbook. Of the 15 included studies, 8 studies performed the intervention in an outpatient setting ${ }^{11,18,21-23,26,27,30}$ and 4 in an inpatient setting. ${ }^{12,19,24,29}$ Three studies included patients from both in- and outpatient settings. ${ }^{28,29,31}$

A total of 842 participants was evaluated, with reported mean ages ranging from 58 to $73 \mathrm{yr}$. Seven studies ${ }^{11,12,19,20,24,25,28}$ included patients with on average severe COPD (mean forced expiratory volume in the first second of expiration $\left[\mathrm{FEV}_{1}\right] 30-50 \%$ predicted), 8 studies $^{18,21,23,26,27,29,30}$ included patients with moderate COPD (mean $\mathrm{FEV}_{1} 50-80 \%$ predicted), and 1 study ${ }^{22}$ included patients with mild COPD (mean $\mathrm{FEV}_{1}>80 \%$ predicted). Most studies had a relatively small sample size $(<50$ patients per group). Only Mesquita et $\mathrm{al}^{28}$ had a sample size of 378 patients. Adverse events were reported only in 4 studies. ${ }^{18,20,30,31}$ The balance measures used in the included studies are briefly described in Table 2 .

\section{INTERVENTION DETAILS}

Study outcomes are described in Table 3. The interventions reported in the included studies often included PR, with or without an additional training component: Two studies focused on the effects of PR only, ${ }^{19,22}$ while 5 studies added an extra training modality to PR (neuromuscular electrical stimulation, ${ }^{21}$ whole-body vibration training, ${ }^{20}$ or balance training $\left.{ }^{11,12,23}\right)$. Leung et $\mathrm{a}^{18}$ used t'ai chi as the only intervention. All studies measured the balance outcomes immediately after the end of the intervention. No outcomes measuring fall risk were reported. 


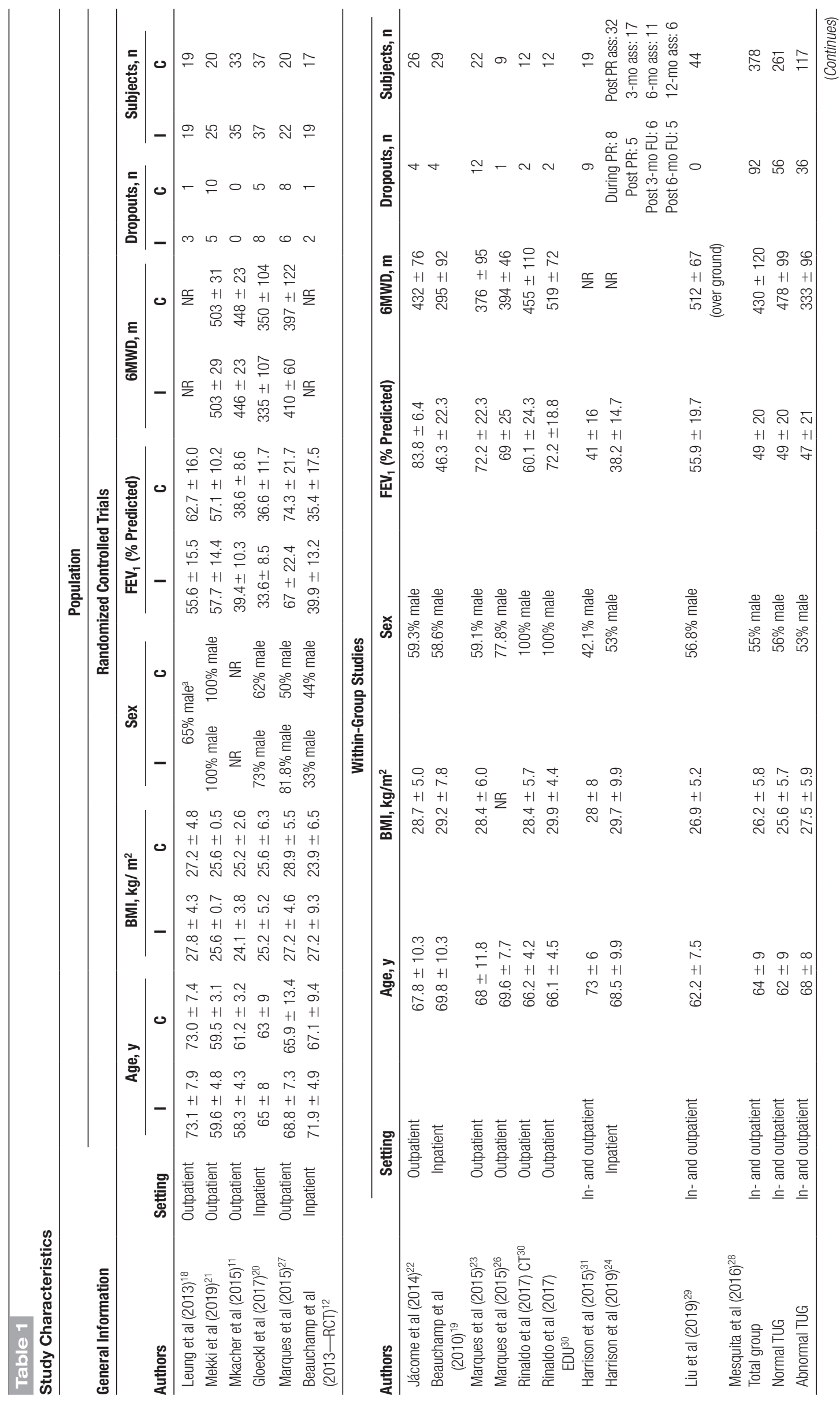




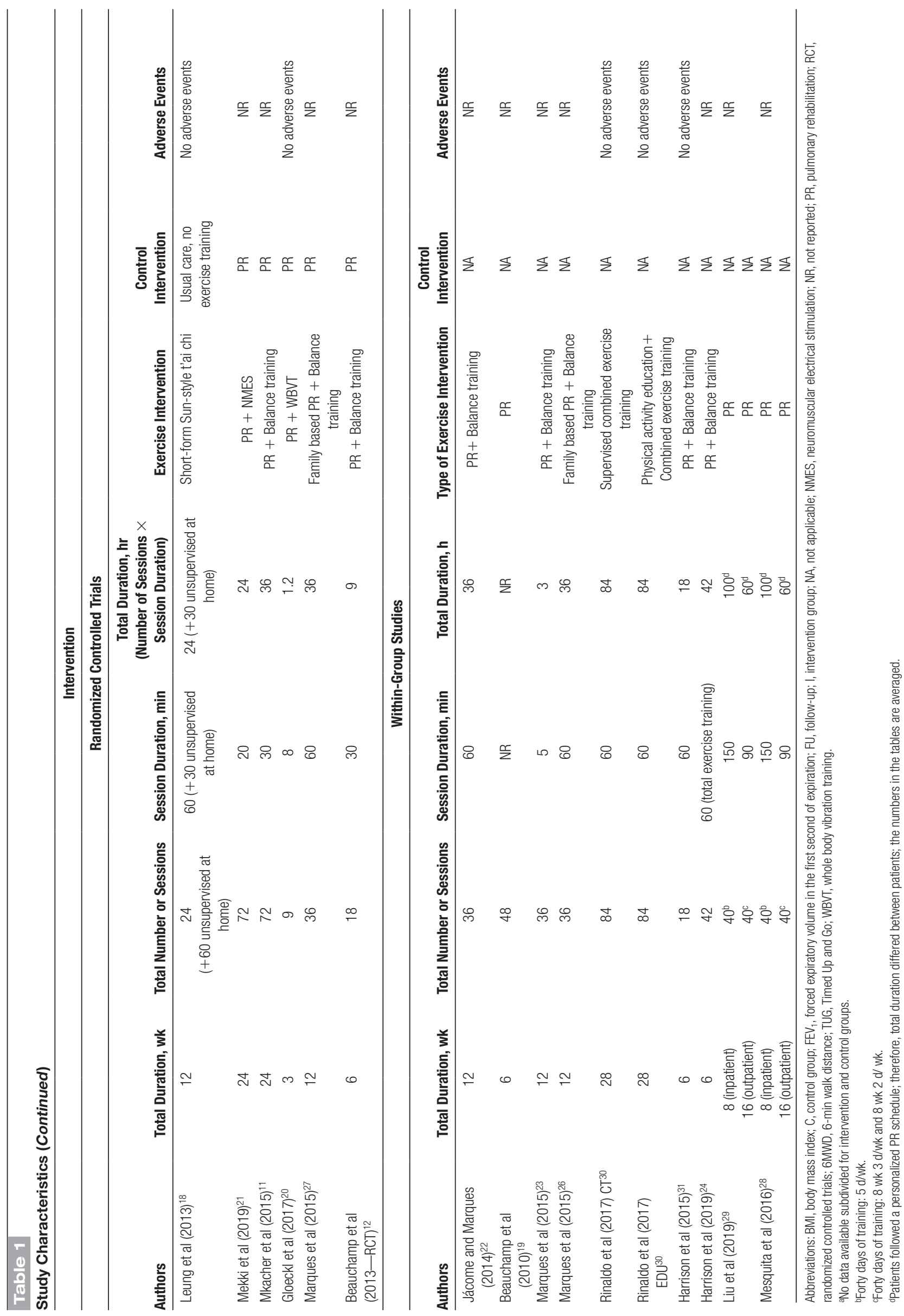




\begin{tabular}{|c|c|c|c|c|}
\hline Instrument & Reported in & Task(s) & Scoring & MCID \\
\hline $\mathrm{BBS}^{46}$ & $\begin{array}{l}\text { Beauchamp et al }(2013- \\
\quad \text { RCT) } \\
\text { Beauchamp et al }(2010)^{19} \text {; } \\
\text { Harrison et al }(2015)^{25} ; \\
\text { Harrison et al }(2019)^{24} \text {; } \\
\text { Mekki et al }(2019)^{21} ; \\
\text { Mkacher et al }(2015)^{11}\end{array}$ & $\begin{array}{l}14 \text { balance-specific tasks (eg, sit to stand, } \\
\text { standing with eyes closed, standing on } 1 \text { leg). } \\
\text { Each task is graded 0-4 depending on the } \\
\text { subjects' performance. }\end{array}$ & $\begin{array}{l}0-56 \text { points }(<46 \text { identifies } \\
\left.\text { risk of falling }{ }^{21}\right)\end{array}$ & 5 points ${ }^{17}$ \\
\hline BESTest $^{47}$ & $\begin{array}{l}\text { Beauchamp et al }(2013- \\
\quad \text { RCT) } \\
\text { Harrison et al }(2015)^{25} \text {; } \\
\text { Harrison et al }(2019)^{24}\end{array}$ & $\begin{array}{l}36 \text { tasks divided over } 6 \text { subsystems } \\
\text { (biomechanical, stability, transitions, reactive, } \\
\text { sensory, and gait). Each task is graded 0-3 } \\
\text { depending on the subject's performance. }\end{array}$ & 0-108 points (higher is better) & 13 points $^{17}$ \\
\hline Body sway 48 & Leung et al $(2013)^{18}$ & $\begin{array}{l}\text { The subject is asked to stand still on a foam } \\
\text { rubber mat for } 30 \text { sec in different positions } \\
\text { (with feet side-by-side and with } 1 \text { foot beside } \\
\text { and behind the other (semitandem stand). The } \\
\text { displacement of the subject's body at waist } \\
\text { level is measured in mm in both anterior- } \\
\text { posterior direction and mediolateral direction. }\end{array}$ & $\begin{array}{l}\text { Displacement in mm per } \\
\text { position (lower is better) }\end{array}$ & NA \\
\hline $\begin{array}{l}\text { Stabilometric platform } \\
\text { test }^{21}\end{array}$ & Mekki et al (2019) ${ }^{21}$ & $\begin{array}{l}\text { The center of pressure (CoP) displacement in the } \\
\text { mediolateral (ML) direction, the anterior- } \\
\text { posterior (AP) direction, and the center of } \\
\text { pressure area is recorded in an upright } \\
\text { standing position, with eyes open and eyes } \\
\text { closed during } 25 \text { and } 6 \mathrm{sec}\end{array}$ & $\begin{array}{l}\text { CoP displacement in } \mathrm{mm} \\
\mathrm{CoP} \text { area in square } \mathrm{mm} \\
\text { (lower is better) }\end{array}$ & NA \\
\hline Functional reach ${ }^{49}$ & Leung et al (2013) ${ }^{18}$ & $\begin{array}{l}\text { Subject is asked to perform a maximal forward } \\
\text { reach using a fixed base of support. The } \\
\text { functional reach is determined as the } \\
\text { difference in cm between arm's length and } \\
\text { the maximal forward reach. }\end{array}$ & Reach in cm (higher is better) & NA \\
\hline $\begin{array}{l}\text { APL during: Romberg } \\
\text { stance, semitandem, } \\
\text { one-leg stance }{ }^{20}\end{array}$ & Gloeckl et al $(2017)^{20}$ & $\begin{array}{l}\text { APL of the center of pressure is measured during } \\
10 \text { sec in the following positions: } \\
\text { With feet side-by-side and eyes closed } \\
\text { With } 1 \text { foot beside and behind the other with } \\
\text { both eyes open and eyes closed } \\
\text { Standing on } 1 \text { leg with eyes open }\end{array}$ & $\begin{array}{l}\text { APL in mm per position (lower } \\
\text { is better) }\end{array}$ & NA \\
\hline Tinetti50 & Mkacher et al (2015) ${ }^{11}$ & $\begin{array}{l}16 \text { tasks ( } 9 \text { balance tasks, } 7 \text { gait tasks). Each } \\
\text { task is graded ( } 0-1 \text { or } 0-2) \text { depending on the } \\
\text { subject's performance. }\end{array}$ & $\begin{array}{l}\text { 0-28 points ( }<26 \text { points } \\
\text { identifies risk of falling }{ }^{11} \text { ) }\end{array}$ & NA \\
\hline TUG $^{32}$ & $\begin{array}{l}\text { Beauchamp et al (2010); } \\
\text { Jacomé and Marques }(2014)^{22} ; \\
\text { Marques et al }(2015)^{23} ; \\
\text { Marques et al }(2015)^{26} \\
\text { Mekki et al }(2019)^{21} \\
\text { Mesquita et al }(2016)^{28} \\
\text { Mkacher et al }(2015)^{11} \\
\text { Liu et al }(2019)^{29}\end{array}$ & $\begin{array}{l}\text { The subject is asked to stand up from a chair, } \\
\text { walk back and forth over a 3-m track and sit } \\
\text { down in the chair. The time to complete is } \\
\text { recorded. }\end{array}$ & $\begin{array}{l}\text { Time in sec }(>16 \text { sec identifies } \\
\left.\quad \text { risk of falling }{ }^{11}\right)\end{array}$ & $0.9-1.4 \sec ^{17}$ \\
\hline Timed 1-leg stance ${ }^{51}$ & Rinaldo et al $(2017)^{30}$ & $\begin{array}{l}\text { The subject is asked to stand on } 1 \text { leg as long as } \\
\text { possible, with a maximum of } 1 \text { min. The test } \\
\text { is stopped when the contralateral foot touches } \\
\text { the ground or } 1 \text { min has passed. The best } 2 \\
\text { separate trials for each limb are summed to } \\
\text { calculate the total time. }\end{array}$ & $\begin{array}{l}\text { Combined time of best trials } \\
\text { right and left leg in seconds } \\
\text { (higher is better) }\end{array}$ & NA \\
\hline UST ${ }^{52}$ & Mkacher et al $(2015)^{11}$ & $\begin{array}{l}\text { The subject is asked to maintain a unipedal } \\
\text { stance for as long as possible (maximum } 45 \\
\text { sec) on his or her leg of preference, while } \\
\text { keeping his or her legs from touching. The } \\
\text { test is stopped when the stance foot is shifted, } \\
\text { the lifted foot touches the floor, or } 45 \text { sec } \\
\text { have passed. The duration of the unipedal } \\
\text { stance is recorded. }\end{array}$ & $\begin{array}{l}\text { Time in seconds (higher is } \\
\text { better) }\end{array}$ & NA \\
\hline
\end{tabular}

Abbreviations: APL, absolute path length; BBS, Berg Balance Scale; BESTest, balance evaluation systems test; cm, centimeter; MCID, minimal clinical importance difference; mm, millimeter; NA, not applicable; RCT, randomized controlled trial; TUG, Timed Up and Go; UST, unipedal stance time. 


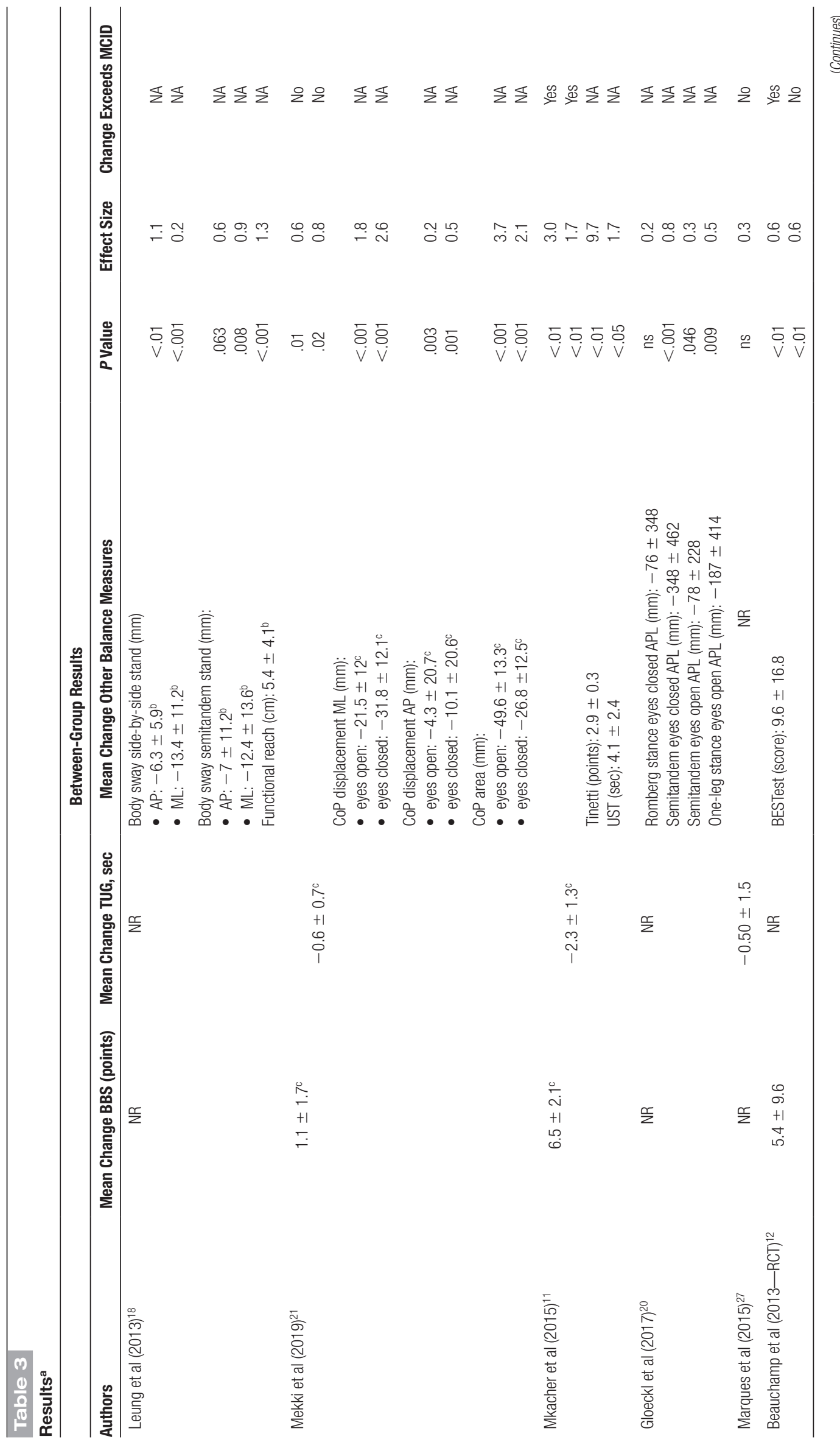




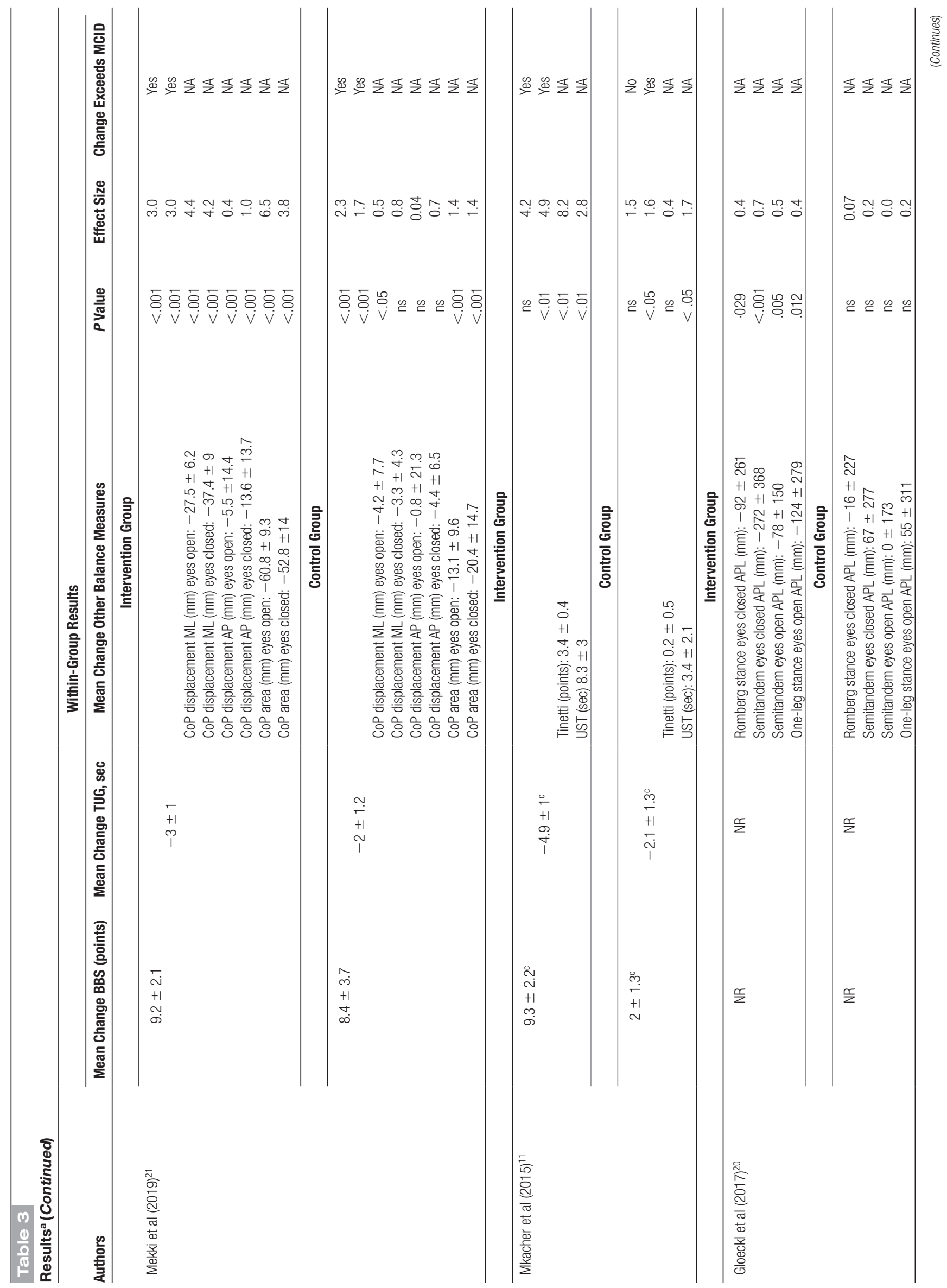




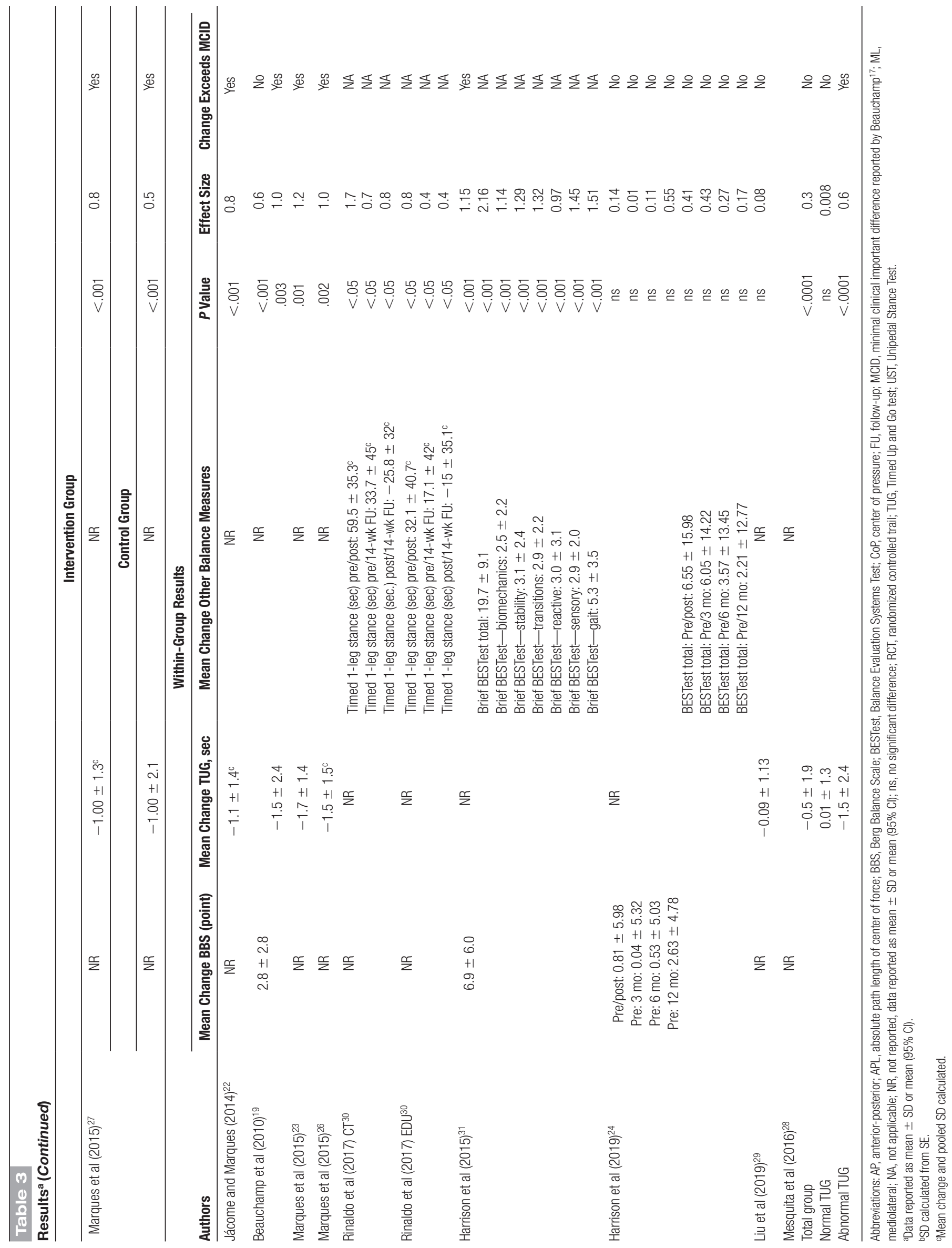




\section{Pulmonary Rehabilitation}

Three studies that performed only conventional PR 19,28,29 used a within-group study design to investigate the effect of PR on balance. One study ${ }^{19}$ used a 6 -wk inpatient setting and 2 studies ${ }^{28,29}$ were performed in a mixed in-/outpatient setting where the outpatient PR program took $16 \mathrm{wk}$ and the inpatient PR program took $8 \mathrm{wk}$. All within-group studies used the Timed Up and Go (TUG) test and 2 studies found significant improvements after PR, ${ }^{19,28}$ which also exceeded the $\operatorname{MCID}^{17}(P=.003$, effect size [ES]: $1.0, P<.001$, ES: 0.3$)$. Beauchamp et $\mathrm{al}^{19}$ used the Berg Balance Scale (BBS) as an additional measure of balance. Although improvements were significant $(P<.001$, ES: 0.6$)$, the MCID was not exceeded. Mesquita et $\mathrm{al}^{28}$ also reported stratified results for normal and abnormal TUG at baseline, with significant improvements only in the group with the abnormal TUG at baseline $(P<.001$, ES: 0.6).

\section{Balance Training Combined With PR}

Two studies ${ }^{11,12}$ investigated the specific effect of adding balance training to PR through an RCT design. Both studies added the balance training program as described by Beauchamp et $a{ }^{12}$ which consists of a combination of stance exercises, transition exercises, gait exercises, and functional strengthening with a progressively increased difficulty level. After a 24-wk outpatient program, Mkacher et $\mathrm{al}^{11}$ found significant improvements in TUG in both groups (intervention group [I]: $P<.01$ and ES: 4.9 , control group [C]: $P$ $<.05$ and ES: 1.6), also exceeding the MCID, while BBS did not change. Significant between-group differences were found for both TUG and BBS $(P<.01$, ES: $1.7 ; P<.01$, ES: $3.0)$, also exceeding MCID. Beauchamp et al $^{12}$ added balance training to a 6-wk inpatient PR program and used the BBS and Balance Evaluation Systems Test (BESTest) as measure for balance. Although for both outcomes a significant difference between the control group and the intervention group was found $(P<.01$, ES: 0.6$)$, only the differences in BBS exceeded the MCID.

Four studies ${ }^{22-24,31}$ used a within-group design to assess the effect of PR with balance training. Two studies ${ }^{22,23}$ used a 12-wk outpatient PR setting with TUG as the outcome measure of balance and found significant $(P<.001$, ES: $0.8 ; P=.001$, ES: 1.2$)$ and clinically relevant improvements. One study ${ }^{31}$ was focused on reducing the gap between evidence and practice by training the health care professionals in knowledge translation before implementing the balance training in the 6-wk PR program with a combined in- and outpatient setting. They used the previously mentioned results from Beauchamp et $\mathrm{al}^{12}$ as a comparison and also followed the same balance training program. Significant results were found in all outcome measures (BBS: $P$ $<.001$, ES: 1.2; BESTest total: $P<.001$, ES: 2.2; BESTest subscores: $P<.001$, ES ranged from 1.0-1.5). One study ${ }^{24}$ used a 6-wk inpatient PR setting with balance training but found no significant improvements on the BBS and BESTest. This was also the only study that assessed the longterm effects of an intervention. Unfortunately, due to a high dropout rate, only $14 \%$ of the initial number of recruited subjects completed the 12-mo follow-up. No significant differences were found when comparing pre-PR results with post-PR measurements and follow-up measurements.

Two studies ${ }^{26,27}$ used a slightly modified version of PR called family-based PR, where family members were more involved during the PR program. This program also included balance training, although balance was not the main outcome of the studies. Both studies used the TUG as a measure of functional balance. One of these studies ${ }^{27}$ was designed as an RCT, in which the control group consisted of PR with bal- ance training but without the increased involvement of family members. Both groups showed significant improvements in the TUG (I: $P<.001$, ES: 0.8; C: $P<.001$, ES: 0.5), and no between-group differences were found. The within-group study ${ }^{26}$ also showed significant improvements when comparing pre- with post-intervention results $(P=.002$, ES: 1.0$)$.

\section{Other Training Interventions Combined With PR}

Mekki et $\mathrm{al}^{21}$ investigated the effect of adding neuromuscular electrical stimulation of several leg muscles to $24 \mathrm{wk}$ of PR. Berg Balance Scale and TUG test were used, along with measures of center of pressure $(\mathrm{CoP})$ displacement in anterior-posterior and mediolateral directions, as well as $\mathrm{CoP}$ area. All CoP measures were tested with eyes open and eyes closed. The intervention group showed significant improvements in all balance measures (BBS: $P<.001$, ES: 3.0; TUG: $P<.001$, ES: 3.0 ; all CoP measures: $P<.001$, ES ranged from 0.4-6.5). The improvements in TUG and BBS exceeded MCID. The control group that received only PR improved significantly in BBS and TUG (BBS: $P<.001$, ES: 2.3; TUG: $P<.001$, ES: 1.7 ), also exceeding MCID, while only 3 of $6 \mathrm{CoP}$ measures showed significant improvements (CoP displacement mediolateral eyes open: $P<0.05$, ES: 0.5; CoP area eyes open and eyes closed: $P<.001$, ES: 1.4$)$. Berg Balance Scale and TUG differed significantly between the intervention and control groups (BBS: $P=.01$, ES: 0.6 ; TUG: $P=.02$, ES: 0.8 ), but this difference did not exceed the MCID.

Gloeckl et $\mathrm{al}^{20}$ used whole-body vibration training as an added intervention to 3 wk of PR. Only balance measures in stance were used, where the absolute path length of the center of force was measured using a force plate. All balance measures improved significantly in the intervention group $(P$ values ranged from $<.001-.029$, effect sizes ranged from 0.4-0.7), while no significant differences were found in the control group. When comparing the intervention group with the control group, all balance measures differed significantly, with the exception of the Romberg stance eyes closed absolute path length.

\section{Other Interventions}

Two studies used exercise-based interventions without PR. Leung et $\mathrm{al}^{18}$ used $12 \mathrm{wk}$ of t'ai chi training 2 times/wk as a training modality for the intervention group, while the control group received usual medical care without exercise training. The outcome measures were body sway in anterior-posterior and mediolateral directions, with feet in semitandem or side-by-side position, and functional reach distance. All balance outcomes, except body sway in semitandem in anterior-posterior direction, significantly improved after the intervention $(P<.01$, ES ranged from 0.2-1.1).

Rinaldo et $\mathrm{al}^{30}$ performed a study in which patients were randomly assigned to one of the intervention groups. One group (CT) received 28 wk of supervised combined exercise training $3 \mathrm{~d} / \mathrm{wk}$. The other group (EDU) received a 28 -wk physical activity education program that consisted of a combination of both supervised and self-directed training sessions. The total of supervised and self-directed sessions added up to 3 times/wk. Balance was assessed using the timed 1-leg stance. Both groups showed significant improvements that remained significant after a follow-up period of $14 \mathrm{wk}$ (CT: $P<.05$, ES ranged from 0.8-1.7; EDU: $P<.05$, ES ranged from 0.4-0.8). No between-group differences were found.

\section{DISCUSSION}

This is the first review systematically evaluating the effects of exercise-based interventions on balance and fall risk in 
patients with COPD. As balance impairment is a common problem in patients with COPD, which contributes to an increased risk of falling, identification of exercise-based interventions that are effective in improving balance in COPD is important. ${ }^{2,3,12}$ Moreover, good balance control is believed to be fundamental in the ability to maintain functional independence in activities of daily living. ${ }^{7}$ Findings of this review indicate that exercise-based interventions are effective in improving balance in patients with COPD. All included articles reported positive effects on balance outcomes after intervention, often exceeding the MCID.

In this review, a wide variety of exercise-based interventions with duration ranging from 3-28 wk was included. Of the 15 studies included in this review, 6 studies used a randomized controlled design $11,12,18,20,21,27$ while 9 studies performed pre-/post-intervention comparisons ${ }^{19,22-24,26,28,29,31}$ or compared 2 interventions. ${ }^{30}$

A large number of outcome measures was used to assess balance. Recently, Beauchamp ${ }^{17}$ provided a critical evidence-based overview of balance measurement in patients with COPD, including TUG, BBS, BESTest, and Mini-BESTest. The TUG, BBS, BESTest, and Mini-BESTest were described to be useful in assessing balance in patients with COPD, with documented construct validity and intra- and interrater reliability. The TUG, BBS, BESTest, and Mini-BESTest are considered reliable and validated measures of balance and have an adequate accuracy in assessing fall status and/or fall risk..$^{28,32-35}$ Looking at studies that reported TUG, BBS, and BESTest (Mini-BESTest was not used in any of the included studies), PR with added balance training has the highest effect size. Fall risk was not reported in any of the included studies.

Three studies ${ }^{18,20,30}$ did not use any of the recommended tools for balance assessment in patients with COPD. Instead, they used single task instruments, such as the functional reach test or 1-leg stance, or instruments that assess only body sway in a specific standing position. Although these tests are less physically demanding, the comprehensiveness of these instruments in assessing functional balance is very limited. Balance can be influenced by many factors, including muscle strength. ${ }^{36}$ Therefore, the results of the studies using single-task instruments might not be as relevant as the results of the studies that used the recommended comprehensive balance assessment tools.

Looking at the quality of the studies, 9 studies ${ }^{11,21-24,27-29,31}$ had an increased risk of bias. This was due to the lack of blinding of outcome assessors. While blinding of participants and persons performing the intervention is sometimes not possible, due to the nature of the intervention, the blinding of outcome assessors was not hindered by this. Also, a high number of dropouts ${ }^{23,24,31}$ and uncertainty about the concealment of the allocation sequence ${ }^{11}$ negatively impacted the risk of bias. Two studies ${ }^{26,30}$ did not provide sufficient information to assess the risk of bias.

No study reported the effects of dual-task training, virtual reality training, or perturbation-based training. A review by de Amorim et $\mathrm{al}^{37}$ concluded that findings of studies using virtual reality training in elderly populations showed promising results. In a review by Ghai et al, ${ }^{38}$ beneficial effects of dual-task training in fall-prone elderly populations were demonstrated. Furthermore, in a review by McCrum et al, ${ }^{39}$ the majority of the included studies showed beneficial effects of perturbation-based training on the reactive recovery response in elderly populations. Moreover, it has been shown that elderly populations are able to adapt locomotion, although the rate of adaptation was decreased compared with younger adults. ${ }^{40}$ In addition, retainment of favorable effects up to a year after exposure to perturbation-based training has been reported in older adults. ${ }^{41,42}$ It would be interesting to demonstrate whether these training modalities provide beneficial effects in patients with COPD. Furthermore, novel outcomes such as margins of stability ${ }^{43,44}$ could provide us with new information on the causes of balance impairment in COPD, enabling us to target balance problems more specifically in patients with COPD.

This review has several limitations. First, only 15 studies were eligible for inclusion. Including studies in languages other than English might have resulted in more eligible articles, although it has been suggested that the exclusion of non-English studies does not affect the results. ${ }^{16}$ Furthermore, since balance assessment and training in COPD are emerging topics for research, it is understandable that a limited amount of records was available at the time of the search. Second, almost all studies included in this review had a relatively small sample size. It would be recommended to perform more studies with a larger sample size, so that results can be generalized to the whole COPD population. Third, most studies performed an intervention in which PR was included. Patients in an earlier stage of COPD or patients who are less limited by their symptoms are less likely to participate in a PR program. Therefore, these patients might not be sufficiently represented in this review. Fourth, due to the diversity of the studies, no meta-analysis was performed, which is in accordance with Cochrane guidelines. ${ }^{16}$ Finally, little is known on long-term effects of the interventions in patients with COPD. All outcomes were measured immediately after the end of the intervention. Only 1 study $^{24}$ followed patients for 12 mo after the intervention but found no significant effect of the intervention and suffered from a high dropout rate during follow-up. It is still unclear whether positive effects measured after interventions will sustain in the long-term. Although immediate beneficial effects of an intervention are a good starting point, the ultimate goal should be to find an intervention that has the ability to maintain a positive effect for a longer period of time. A sustained effect of an intervention that improves balance and decreases fall risk would provide a good rationale for implementing such an intervention in usual care. Although exercise interventions such as perturbation training have shown beneficial long-term effects in the elderly, ${ }^{40,42}$ a combination of behavioral and exercise interventions will probably be necessary to optimize preservation of beneficial effects in patients with COPD.

Considering the increased risk of falls associated with COPD as well as increased mortality, interventions focusing on balance improvement in patients with COPD are important. The American Thoracic Society/European Respiratory Society statement on PR has also reported that balance should be one of the outcome assessments of PR. ${ }^{9}$ This review confirms previous findings that a standardized measure of balance in COPD is currently lacking. ${ }^{17,45}$ Indeed, a large variety in outcome measures was used, and instructions for the tests were not standardized. For example, some studies instructed the patients for the TUG to stand up from a chair, walk as quickly and safely as possible back and forth on a 3-m course, and sit down, 22,23,27 while others instructed patients to walk at a comfortable pace..$^{11,19,28,29}$ It seems necessary to determine a standardized balance assessment to be able to adequately assess effects of different interventions.

\section{CONCLUSIONS}

Exercise-based interventions have the potential to improve balance in patients with COPD. Pulmonary rehabilitation combined with balance training showed the most beneficial effect on balance, when considering the recommended 
balance assessment instruments. Whether and to what extent these interventions also have a positive effect on fall risk remains currently unknown.

\section{ACKNOWLEDGMENTS}

The authors thank Dr Regina Leung (Concord Repatriation General Hospital, Sydney, Australia), Dr Samantha Harrison (Teesside University, Middleborough, United Kingdom), Dr Dina Brooks (West Park Healthcare Centre, Ontario, Canada), Dr Marla Beauchamp (McMaster University, Ontario, Canada), Dr Rainer Gloeckl (Schoen Klinik Berchtesgadener Land, Schoenau am Koenigssee, Germany), Dr Rafael Mesquita (Horn, the Netherlands), and Dr Wai-Yan Liu (Horn, the Netherlands) for sending additional data to complete this review.

\section{REFERENCES}

1. Ganz DA, Bao Y, Shekelle PG, Rubenstein LZ. Will my patient fall? JAMA. 2007;297(1):77-86.

2. Porto EF, Castro AA, Schmidt VG, et al. Postural control in chronic obstructive pulmonary disease: a systematic review. Int J Chron Obstruct Pulmon Dis. 2015;10:1233-1239.

3. Roig M, Eng JJ, MacIntyre DL, et al. Falls in people with chronic obstructive pulmonary disease: an observational cohort study. Res Med. 2011;105(3):461-469.

4. Roig M, Eng JJ, Road JD, Reid WD. Falls in patients with chronic obstructive pulmonary disease: a call for further research. Res Med. 2009;103(9):1257-1269.

5. Smith MD, Chang AT, Seale HE, Walsh JR, Hodges PW. Balance is impaired in people with chronic obstructive pulmonary disease. Gait Posture. 2010;31(4):456-460.

6. Roig M, Eng JJ, Macintyre DL, Road JD, Reid WD. Postural control is impaired in people with COPD: an observational study. Physiother Can. 2011;63(4):423-431.

7. Iwakura M, Okura K, Shibata K, et al. Relationship between balance and physical activity measured by an activity monitor in elderly COPD patients. Int J Chron Obstruct Pulmon Dis. 2016;11:1505-1514.

8. Singh D, Agusti A, Anzueto A, et al. Global strategy for the diagnosis, management, and prevention of chronic obstructive lung disease: the GOLD science committee report 2019. Eur Respir J. 2019;53(5).

9. Spruit MA, Singh SJ, Garvey C, et al. An official American Thoracic Society/European Respiratory Society statement: key concepts and advances in pulmonary rehabilitation. Am J Respir Crit Care Med. 2013;188(8):e13-e64.

10. Yohannes AM, Raue PJ, Kanellopoulos D, et al. Predictors of allcause mortality in patients with severe COPD and major depression admitted to a rehabilitation hospital. Chest. 2016;149(2):467-473.

11. Mkacher W, Mekki M, Tabka Z, Trabelsi Y. Effect of 6 months of balance training during pulmonary rehabilitation in patients with COPD. J Cardiopulm Rehabil Prev. 2015;35(3):207-213.

12. Beauchamp MK, Janaudis-Ferreira T, Parreira V, et al. A randomized controlled trial of balance training during pulmonary rehabilitation for individuals with COPD. Chest. 2013;144(6):1803-1810.

13. Moher D, Liberati A, Tetzlaff J, Altman DG, The PRISMA Group. Preferred reporting items for systematic reviews and meta-analyses: the PRISMA statement. PLOS Med. 2009;6(7):e1000097.

14. Savovic J, Page M, Elbers R, et al. A revised tool for assessing risk of bias in randomized trials (RoB 2.0). BMJ. 2019;366:14898.

15. Sterne JA, Hernan MA, Reeves BC, et al. ROBINS-I: a tool for assessing risk of bias in non-randomised studies of interventions. BMJ (Clinical research ed). 2016;355:14919.

16. Higgins JPT, Green S. Cochrane Handbook for systematic reviews of interventions. The Cochrane Collaboration Web site. www.handbook.cochrane.org. Published 2011. Updated March 2011. Accessed November 25, 2019

17. Beauchamp MK. Balance assessment in people with COPD: an evidence-based guide. Chron Respir Dis. 2019;16:1479973118820311.

18. Leung RWM, McKeough ZJ, Peters MJ, Alison JA. Short-form Sun-style t'ai chi as an exercise training modality in people with COPD. Eur Respir J. 2013;41(5):1051-1057.
19. Beauchamp MK, O’Hoski S, Goldstein RS, Brooks D. Effect of pulmonary rehabilitation on balance in persons with chronic obstructive pulmonary disease. Arch Phys Med Rehabil. 2010;91(9):1460-1465.

20. Gloeckl R, Jarosch I, Bengsch U, et al. What's the secret behind the benefits of whole-body vibration training in patients with COPD? A randomized, controlled trial. Respir Med. 2017;126:17-24.

21. Mekki M, Paillard T, Sahli S, Tabka Z, Trabelsi Y. Effect of adding neuromuscular electrical stimulation training to pulmonary rehabilitation in patients with chronic obstructive pulmonary disease: randomized clinical trial. Clin Rehabil. 2019;33(2):195-206.

22. Jácome C, Marques A.Impact of pulmonary rehabilitation in subjects with mild COPD. Respir Care. 2014;59(10):1577-1582.

23. Marques A, Jácome C, Cruz J, Gabriel R, Figueiredo D. Effects of a pulmonary rehabilitation program with balance training on patients with COPD. J Cardiopulm Rehabil Prev. 2015;35(2):154-158.

24. Harrison SL, Araujo T, Goldstein R, Brooks D. Balance measures over 12 months in individuals with chronic obstructive pulmonary disease. J Cardiopulm Rehabil Prev. 2019;39(3):E21-E24.

25. Harrison SL, Beauchamp MK, Sibley K, et al. Minimizing the evidence-practice gap - a prospective cohort study incorporating balance training into pulmonary rehabilitation for individuals with chronic obstructive pulmonary disease. BMC Pulm Med. 2015;15:73.

26. Marques A, Gabriel R, Jacome C, Cruz J, Brooks D, Figueiredo D. Development of a family-based pulmonary rehabilitation programme: an exploratory study. Disabil Rehabil. 2015;37(15):1340-1346.

27. Marques A, Jacome C, Cruz J, Gabriel R, Brooks D, Figueiredo D. Family-based psychosocial support and education as part of pulmonary rehabilitation in COPD: a randomized controlled trial. Chest. 2015;147(3):662-672.

28. Mesquita R, Wilke S, Smid DE, et al. Measurement properties of the Timed Up \& Go test in patients with COPD. Chron Respir Dis. 2016;13(4):344-352.

29. Liu WY, Meijer K, Delbressine JM, Willems PJ, Wouters EF, Spruit MA. Effects of pulmonary rehabilitation on gait characteristics in patients with COPD. J Clin Med. 2019;8(4):459.

30. Rinaldo N, Bacchi E, Coratella G, et al. Effects of combined aer obic-strength training vs fitness education program in COPD patients. Int J Sports Med. 2017;38(13):1001-1008.

31. Harrison SL, Beauchamp MK, Sibley K, et al. Minimizing the evidence-practice gap-a prospective cohort study incorporating balance training into pulmonary rehabilitation for individuals with chronic obstructive pulmonary disease. BMC Pulm Med. 2015;15:73.

32. Podsiadlo D, Richardson S.The Timed "Up \& Go": a test of basic functional mobility for frail elderly persons. J Am Geriatr Soc. 1991;39(2):142-148

33. Mesquita R, Janssen DJ, Wouters EF, Schols JM, Pitta F, Spruit MA. Within-day test-retest reliability of the Timed Up \& Go test in patients with advanced chronic organ failure. Arch Phys Med Rehabil. 2013;94(11):2131-2138.

34. Jacome C, Cruz J, Oliveira A, Marques A. Validity, reliability, and ability to identify fall status of the Berg Balance Scale, BESTest, Mini-BESTest, and Brief-BESTest in patients with COPD. Phys Ther. 2016;96(11):1807-1815.

35. Magnani PE, Genovez MB, Porto JM, et al. Use of the BESTest and the Mini-BESTest for fall risk prediction in communitydwelling older adults between 60 and 102 years of age. J Geriatr Phys Ther (2001). Published online May 6, 2019. doi: 10.1519/ JPT.0000000000000236

36. McLay R, O'hoski S, Beauchamp MK. Role of muscle strength in balance assessment and treatment in chronic obstructive pulmonary disease. Cardiopulm Phys Ther J. 2019;30(1):35-43.

37. de Amorim JSC, Leite RC, Brizola R, Yonamine CY. Virtual reality therapy for rehabilitation of balance in the elderly: a systematic review and META-analysis. Adv Rheumatol (London, England). 2018;58(1):18

38. Ghai S, Ghai I, Effenberg AO. Effects of dual tasks and dual-task training on postural stability: a systematic review and meta-analysis. Clin Interv Aging. 2017;12:557-577.

39. McCrum C, Gerards MHG, Karamanidis K, Zijlstra W, Meijer K. A systematic review of gait perturbation paradigms for improving reactive stepping responses and falls risk among healthy older adults. Eur Rev Aging Phys Act. 2017;14:3.

40. McCrum C, Epro G, Meijer K, Zijlstra W, Bruggemann GP, Karamanidis K. Locomotor stability and adaptation during 
perturbed walking across the adult female lifespan. J Biomech. 2016;49(7):1244-1247.

41. Pai YC, Bhatt T, Yang F, Wang E. Perturbation training can reduce community-dwelling older adults' annual fall risk: a randomized controlled trial. J Gerontol Series A, Biol Sci Med Sci. 2014;69(12):1586-1594.

42. Epro G, Mierau A, McCrum C, Leyendecker M, Bruggemann GP, Karamanidis K. Retention of gait stability improvements over 1.5 years in older adults: effects of perturbation exposure and triceps surae neuromuscular exercise. J Neurophysiol. 2018;119(6):2229-2240.

43. Sivakumaran S, Schinkel-Ivy A, Masani K, Mansfield A. Relationship between margin of stability and deviations in spatiotemporal gait features in healthy young adults. Hum Mov Sci. 2018;57:366-373.

44. Hof AL, Gazendam MG, Sinke WE. The condition for dynamic stability. J Biomech. 2005;38(1):1-8.

45. Oliveira CC, Lee A, Granger CL, Miller KJ, Irving LB, Denehy L. Postural control and fear of falling assessment in people with chronic obstructive pulmonary disease: a systematic review of instruments, international classification of functioning, disability and health linkage, and measurement properties. Arch Phys Med Rehabil. 2013;94(9):1784-1799. e1787.
46. Berg KO, Wood-Dauphinee SL, Williams JI, Maki B. Measuring balance in the elderly: validation of an instrument. Can J Public Health. 1992;83(suppl 2):S7-S11.

47. Horak FB, Wrisley DM, Frank J. The Balance Evaluation Systems Test (BESTest) to differentiate balance deficits. Phys Ther. 2009;89(5):484-498.

48. Lord SR, Menz HB, Tiedemann A. A physiological profile approach to falls risk assessment and prevention. Phys Ther. 2003;83(3):237-252.

49. Duncan PW, Weiner DK, Chandler J, Studenski S. Functional reach: a new clinical measure of balance. J Gerontol. 1990;45(6):M192M197.

50. Tinetti ME.Performance-oriented assessment of mobility problems in elderly patients. J Am Geriatr Soc. 1986;34(2):119126.

51. Jonsson E, Å Seiger, Hirschfeld H. One-leg stance in healthy young and elderly adults: a measure of postural steadiness? Clin Biomech. 2004;19(7):688-694.

52. Hurvitz EA, Richardson JK, Werner RA, Ruhl AM, Dixon MR. Unipedal stance testing as an indicator of fall risk among older outpatients. Arch Phys Med Rehabil. 2000;81(5):587-591. 